\title{
Integrating risk management data in quality improvement initiatives within an academic neurosurgery department
}

\author{
*Nancy McLaughlin, MD, PhD, FRCSC,' Matthew C. Garrett, MD,' Leila Emami," \\ Sarah K. Foss, MA, ${ }^{2}$ Johanna L. Klohn, MPH, Esq, ${ }^{2}$ and Neil A. Martin, MD ${ }^{1}$ \\ 'Department of Neurosurgery, David Geffen School of Medicine, University of California, Los Angeles; and 2Department of Risk \\ Management, University of California, Los Angeles, California
}

\begin{abstract}
OBJECTIVE While malpractice litigation has had many negative impacts on health care delivery systems, information extracted from lawsuits could potentially guide toward venues to improve care. The authors present a comprehensive review of lawsuits within a tertiary academic neurosurgical department and report institutional and departmental strategies to mitigate liability by integrating risk management data with quality improvement initiatives.

METHODS The Comprehensive Risk Intelligence Tool database was interrogated to extract claims/suits abstracts concerning neurosurgical cases that were closed from January 2008 to December 2012. Variables included demographics of the claimant, type of procedure performed (if any), claim description, insured information, case outcome, clinical summary, contributing factors and subfactors, amount incurred for indemnity and expenses, and independent expert opinion in regard to whether the standard of care was met.

RESULTS During the study period, the Department of Neurosurgery received the most lawsuits of all surgical specialties (30 of 172), leading to a total incurred payment of $\$ 4,949,867$. Of these lawsuits, 21 involved spinal pathologies and 9 cranial pathologies. The largest group of suits was from patients with challenging medical conditions who underwent uneventful surgeries and postoperative courses but filed lawsuits when they did not see the benefits for which they were hoping; $85 \%$ of these claims were withdrawn by the plaintiffs. The most commonly cited contributing factors included clinical judgment (20 of 30), technical skill (19 of 30), and communication (6 of 30).

CONCLUSIONS While all medical and surgical subspecialties must deal with the issue of malpractice and liability, neurosurgery is most affected both in terms of the number of suits filed as well as monetary amounts awarded. To use the suits as learning tools for the faculty and residents and minimize the associated costs, quality initiatives addressing the most frequent contributing factors should be instituted in care redesign strategies, enabling strategic alignment of quality improvement and risk management efforts.
\end{abstract}

http://thejns.org/doi/abs/10.3171/2014.11.JNS132653

KEY WORDS liability; risk management; quality; value; process improvement; culture; neurosurgery

$\mathrm{N}$ EUROSURGERY represents a high-risk specialty for litigation given the necessity of rapid decision making, the potentially unavoidable poor outcomes, and the procedure-driven aspects of this specialty. ${ }^{9,24}$ The litigious nature of our modern society has resulted in an increase in the number of lawsuits as well as the rewarded amounts. ${ }^{6}$ The medical malpractice insurance premiums paid by providers have increased disproportionately to physicians' income ${ }^{8}$ Considering the financial and professional impacts of malpractice liability, physicians practicing high-risk specialties, such as neurosurgeons, have re- considered the scope, geographic location, practice pattern (solo vs group), and total duration of their practice. ${ }^{1,11,22}$ A high percentage of physicians have also adopted a defensive medicine practice, ordering additional laboratory tests, imaging tests/procedures, and consultations. ${ }^{13,24} \mathrm{Al}-$ though defensive medicine may potentially add value to a patient's care, for example, referral to a specialized colleague physician for a second opinion, it can also be detrimental if it results in unnecessary invasive procedures that expose the patient to significant risk or if it incurs expensive additional costs without improving outcome. ${ }^{6,19,25}$

ABBREVIATIONS CRIT = Comprehensive Risk Intelligence Tool; MRMC = Medical Risk Management Committee; RRMC = Ronald Reagan Medical Center; SMMC = Santa Monica Medical Center; UCLA = University of California, Los Angeles.

SUBMITTED December 5, 2013. ACCEPTED November 24, 2014.

INCLUDE WHEN CITING Published online July 31, 2015; DOI: 10.3171/2014.11.JNS132653.

DISCLOSURE The authors report no conflict of interest concerning the materials or methods used in this study or the findings specified in this paper.

* Drs. McLaughlin and Garrett contributed equally to this work. 
From a societal perspective, malpractice liability has also impacted patient care access, with consolidation of emergency neurosurgical coverage and high-risk specialty services at specific facilities, most frequently academic institutions. ${ }^{2,11,22}$ This referral pattern could result in an increase in the number of claims and/or the total claim amount incurred by these institutions. To date, knowledge on malpractice liability has been provided from national or state survey results or data from medical insurance companies. . $^{5,13,18}$

We present a review of liability claims/suits within a tertiary academic neurosurgical department. A detailed review of claim/suit standardized abstracts and comprehensive understanding of contributing factors is reported. Identified opportunities for improvement are integrated in the department's quality improvement initiatives to improve global care delivered. From this unique perspective, departmental engagement is essential to inspire all health care providers to strive for a risk-free environment.

\section{Methods}

\section{Department of Neurosurgery at UCLA}

The neurosurgery faculty of the Department of Neurosurgery of UCLA delivers neurosurgical care at 4 medical centers within UCLA Health: Ronald Reagan Medical Center (RRMC), Santa Monica Medical Center (SMMC) and Orthopedic Hospital, the West Los Angeles VA Medical Center, and the Harbor UCLA Medical Center. From January 2008 to December 2012, a mean of 15 neurosurgeons (minimum 14 and maximum 16) and 18.5 residents (minimum 16 and maximum 20) provided care throughout RRMC and SMMC. The Department of Neurosurgery partnered with the Department of Risk Management to review the malpractice claim/suit data for the department of neurosurgery at RRMC and SMMC over this 5-year period.

\section{Risk Management Department}

In October 2009, the University of California authorized its third party claims administrators, Sedgwick CMS, to retain the services of the Risk Management Foundation of the Harvard Medical Institutions and their program CRIT (Comprehensive Risk Intelligence Tool), to coordinate claims management. The direct management and oversight of CRIT is done through the Risk Management Foundation's affiliated division, Crico Strategies. Crico began reviewing and creating the UC Health database with potentially compensable events, claims, and suits. In February 2012, the program was introduced to the risk management departments within UC Health. Using a coding algorithm, all liability cases throughout UC Health are coded in a standardized fashion. ${ }^{4}$ Each case must be assigned at least one of 15 possible contributing factors: administrative, behavior-related, clinical environment, clinical judgment, communication, clinical system, documentation, environmental, equipment, managed care related, supervision, team factor, technical skills, information limited, or noninsured issue. Within each contributing factor there are also numerous possible subfactors. Importantly, CRIT has categorized contributing factors and subfactors (Fig. 1). ${ }^{4}$ Cases prior to February 2012 were retrospectively entered in the CRIT database.

The CRIT database was interrogated to extract all claims and suits concerning neurosurgical patients cared for either at RRMC or SMMC that were closed from January 2008 to December 2012. To be considered for this study, the original action must have been terminated during the study period and resulted either in claim denied, dismissed voluntarily by the plaintiffs, dismissed by the court, or settled. Each malpractice claim/suit concerned a neurosurgical case but not necessarily a neurosurgeon, as in some instances, no specific physician was noted in the abstract, only RRMC or SMMC.

For each claim/suit, we recorded demographics of the claimant, type of procedure performed (if any), claim description, insured information (physicians, residents, medical center), case outcome, clinical summary, contributing factors and subfactors, amount incurred for indemnity, and expenses.

\section{Determining Negligence}

In civil litigation the plaintiff must prove that the practitioner has been negligent by establishing 4 elements: that a duty was owed, that the duty was breached, that the breach caused the injury, and that there was damage resulting from the injury. The breach in duty is determined by a breach in the standard of care. When evaluating a case, the Department of Risk Management at UCLA utilizes expert reviews and the Medical Risk Management Committee (MRMC) to determine whether the standard of care was met. Additionally, when a case is settled for an amount in excess of $\$ 29,999$ or a verdict for the plaintiff is rendered, the case is reviewed for allocation and mandatory reporting to the Medical Board of California. An allocation committee including the chief medical officer and chief risk officer reviews the case and ultimately makes the recommendation for allocation to the Office of General Counsel at University of California's Office of the President.

For all cases, the findings of the expert review and MRMC as to negligence were considered as well as medical board reporting. In cases in which all 3 elements existed (there was an unfavorable expert review, the MRMC found that the standard of care was breached, and the practitioner(s) were reported to the medical board), the existence of negligence was assumed.

\section{Results}

\section{Overview for RRMC and SMMC}

From January 2008 to December 2012, RRMC and SMMC received a total of 367 filed claims. The annual rate of claims ranged from 69 per year (2009) to 79 per year (2010) (Fig. 2). However, the annual cost associated with these claims climbed from a nadir of $\$ 2,089,893$ in 2008 to a peak of $\$ 8,079,984$ in 2010 (Fig. 2). The increase in total incurred since 2010 is explained by the presence of one annual case that settled for a high amount. Of the 367 claims filed for RRMC and SMMC, 172 involved surgical services (Table 1). The Department of Neurosurgery had the most lawsuits (30 claims) with an annual rate ranging from 2 to 10 per year. Orthopedic surgery 


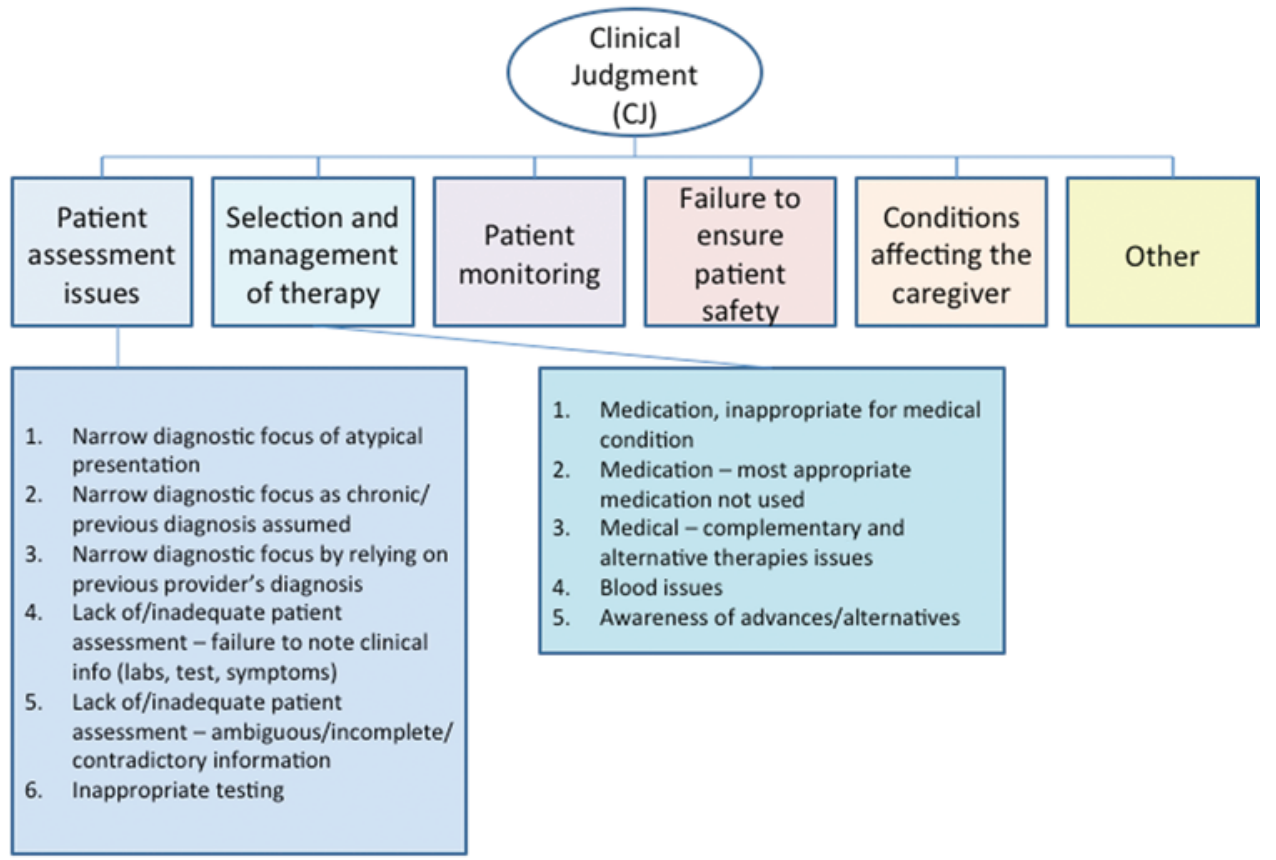

FIG. 1. Example of a contributing factor and its related subfactors. The example of clinical judgment is provided.

(29 claims), ophthalmology (21 claims), otolaryngology (16 claims), and urological surgery (16 claims) were in the top 5 of surgical services with the highest claim counts among surgical specialties (Table 1). The 30 lawsuits filed against the department of neurosurgery led to a total incurred payment of $\$ 4,949,867$. In contrast the 29 claims against orthopedic surgery led to a total incurred payment of $\$ 2,885,914$. The wide variability in payments is largely due to the indemnity paid $(\$ 3,277,799$ neurosurgery vs $\$ 1,444,999$ orthopedic surgery). Interestingly, there was very little correlation between the number of claims and the total cost incurred. Ophthalmology had 21 claims but only incurred $\$ 272,022$. In contrast, colorectal surgery (2 claims) and cardiac surgery (7 claims) incurred costs of $\$ 1,220,094$ and $\$ 2,578,351$, respectively.

Among the 367 lawsuits filed against RRMC and SMMC, the 2 most frequently cited contributing factors were clinical judgment (258 of 367) and technical skill (150 of 367) (Fig. 2). Focusing on all surgical cases managed at RRMC and SMMC excluding neurosurgery, clinical judgment (91 of 172) and technical skill (75 of 172) were again the most commonly cited factors.

\section{Overview of Cases for the Department of Neurosurgery at UCLA}

\section{Claim Overview and Incurred Costs}

The medical center (RRMC or SMMC) was the only identified insured in 7 of the 30 cases filed against the Department of Neurosurgery during the study period. For all other cases, one or multiple medical specialist(s) were specifically named: radiology $(n=2)$, anesthesia $(n$ $=1)$, internal medicine $(\mathrm{n}=1)$, infectious disease $(\mathrm{n}=1)$, general surgery $(n=1)$, and cardiology $(n=1)$. Neurosurgeons were named in the remaining 23 cases. Among the
30 neurosurgical lawsuits closed during the study period, 21 cases involved spinal pathology/procedures and 9 cases involved cranial pathology/procedures (Fig. 3). Regarding the spinal cases, 7 involved the cervical spine, 4 the thoracic spine, and 9 the lumbosacral spine. In 1 spinal case, the involved level was not specified in the case abstract. Regarding the cranial cases, the diagnoses involved were hydrocephalus $(n=3)$, tumor $(n=2)$, pituitary $(n=1)$, epilepsy $(n=1)$, vascular $(n=1)$, and functional $(n=1)$.

Following a similar trend seen at UCLA Health, the total cost incurred (including legal fee expenses and indemnity) associated with all neurosurgery suits increased over time, showing a nadir of $\$ 59,519$ in 2009 and reaching a peak of $\$ 2,436,897$ in 2012 (Fig. 4). Of the 10 neurosurgery claims in 2010, 2 were settled in the amounts of $\$ 120,000$ and $\$ 29,999$. The total amount spent on defending the 10 cases was $\$ 353,418$. Despite the number of claims decreasing in 2011 and 2012, the total indemnity incurred increased significantly $(\$ 1,048,800$ and $\$ 2,030,000$, respectively).

Reviewing the case abstracts of all suits filed against the Department of Neurosurgery (RRMC and SMMC) showed that the majority of these suits fell into one of 2 types. The second largest group (10 suits) included cases in which an intraoperative mistake or equipment failure led to an injury. Seven of these cases resulted in a settlement. The cases that did not result in settlement were dismissed by the plaintiff or denied further consideration when it was decided that the consent sufficiently explained the risk of the given complication. The largest group (13 suits) were patients with challenging medical problems, e.g., chronic back pain, unexplained neurological decline or polytrauma, who underwent uneventful surgeries but filed lawsuits when they did not see the benefits for which they were hoping. Interestingly, after being filed 11 of these 13 suits 

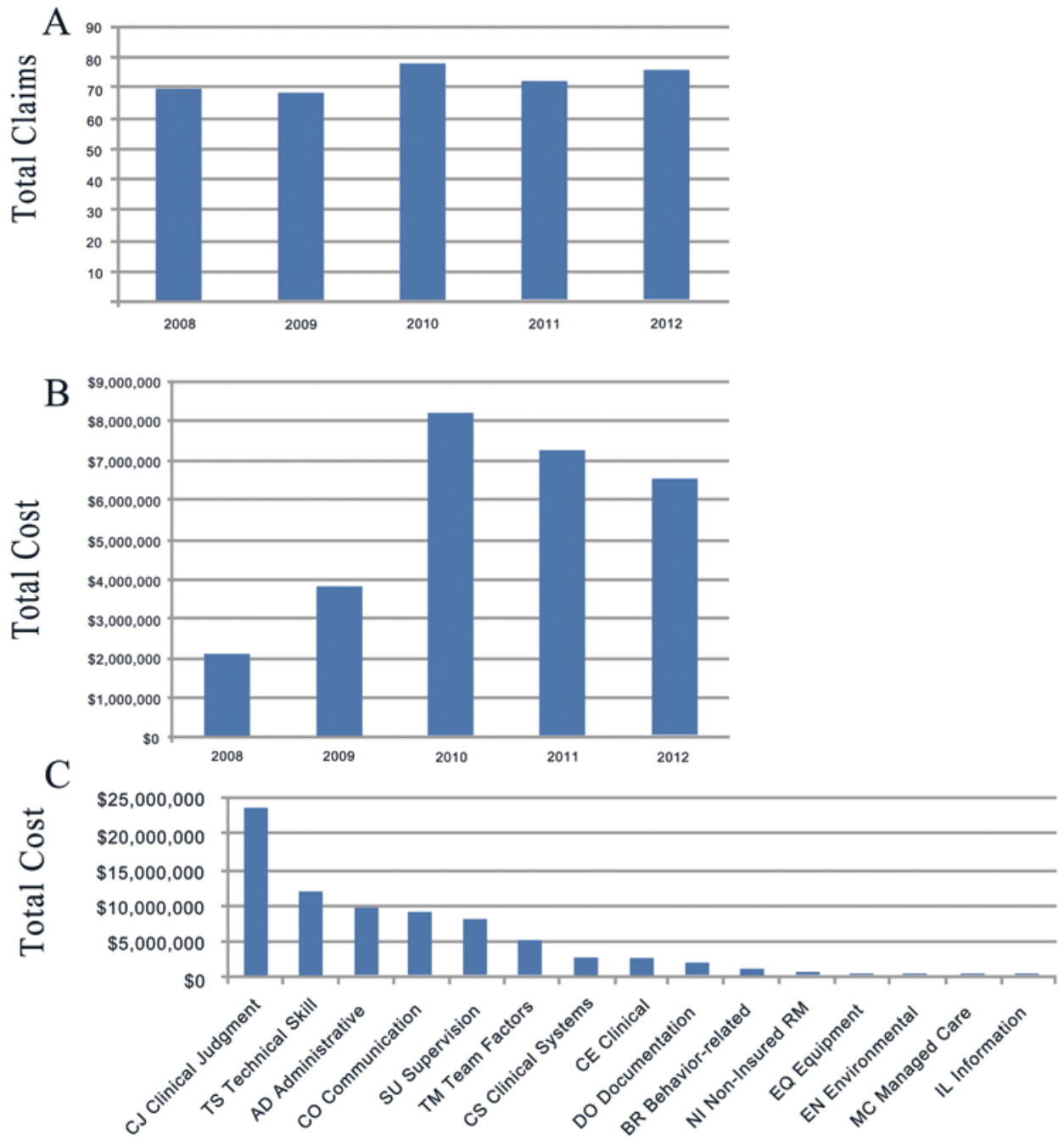

FIG. 2. Bar graphs showing data for all departments of RRMC and SMMC during the study period (2008-2012). A: Representation of the number of claims filed per year. B: Representation of the total cost incurred per year. C: Representation of total cost incurred per contributing factors identified in the lawsuits.

were withdrawn by the plaintiffs. One of these was denied in court and the other was settled because during a previous surgery there had been a pressure-related palsy due to poor positioning. Table 2 presents categories of claims made and the associated outcome.

\section{Contributing Factors and Related Incurred Costs}

Of the 30 lawsuits filed against the Department of Neurosurgery, the top 3 contributing factors were clinical judgment (cited in 20 claims), technical skill (cited in 19 claims), and communication (cited in 9 claims) (Fig. 4). The top 3 subfactors extracted from the claims included technical performance from the category technical skills (noted in 17 claims), patient assessment issues (noted in 14 claims), and selection and management of therapy (noted in 8 claims), both from the category clinical judgment. Table 3 presents clinical examples from the current series of the top 3 subfactors. To determine how detrimental contributing factors were to the final cost of the award/ settlement, we summed the total cost incurred of all cases in which a given contributing factor was identified (Fig. 4). Interestingly, while more lawsuits cited clinical judgment as an instigating cause, suits involving technical skill led to higher monetary awards. While documentation issues were only listed in 3 lawsuits the final judgments of those lawsuits accounted for slightly more than half (50.7\%) of the total awards for all lawsuits. Interestingly, the total monetary assessment for the subfactors technical performance, communication between patient/family and providers, and selection and management of therapy were $\$ 4,316,816, \$ 2,250,085$, and $\$ 1,457,060$, respectively. In contrast, the total cost for all cases that involved patient assessment issues (14 cases) was only \$578,976.

\section{Assessment of Negligence}

Next, we sought to determine whether the providers met the standard of care delivery (absence of negligence), using data from the MRMC outside expert reviews. In 12 of 30 cases no expert opinion was required and no report to the medical board was made. In 11 of 30 cases 
TABLE 1. UCLA RRMC and SMMC claims in surgical specialties closed between 2008 and 2012

\begin{tabular}{lcr}
\hline Surgical Specialty & Claim Count & Total Incurred (in US dollars) \\
\hline Neurosurgery & 30 & $\$ 4,949,867$ \\
\hline Orthopedic surgery & 29 & $\$ 2,885,914$ \\
\hline Ophthalmology & 21 & $\$ 272,022$ \\
\hline Otolaryngology & 16 & $\$ 1,419,669$ \\
\hline Urological surgery & 16 & $\$ 436,384$ \\
\hline Transplant & 14 & $\$ 680,440$ \\
\hline Plastic (NOC) & 9 & $\$ 825,634$ \\
\hline General surgery & 9 & $\$ 652,513$ \\
\hline Cardiac surgery & 7 & $\$ 2,578,351$ \\
\hline Otorhinolaryngology & 5 & $\$ 141,113$ \\
\hline Vascular surgery & 4 & $\$ 396,058$ \\
\hline Oncology & 3 & $\$ 92,592$ \\
\hline Colorectal & 2 & $\$ 1,220,094$ \\
\hline Pediatric surgery & 2 & $\$ 400$ \\
\hline Thoracic surgery & 2 & $\$ 6565$ \\
\hline Bariatric surgery & 1 & $\$ 145$ \\
\hline Hand surgery & 1 & $\$ 74$ \\
\hline Podiatry & 1 & $\$ 66$ \\
\hline
\end{tabular}

NOC $=$ not otherwise classified.

both the expert review and the MRMC were consulted. We identified 6 cases in which the expert review and/or MRMC determined that standard of care was not met or met with concerns and the case was settled and reported to the California Medical Board. All of these suits involved spinal surgeries. In one additional case, expert review and MRMC review were not obtained, the case was settled and reported to the Medical Board of California.
TABLE 2. Categories of claims made toward UCLA medical center and the associated outcome

\begin{tabular}{ll}
\hline \multicolumn{1}{c}{ Category of Claims } & \multicolumn{1}{c}{ Verdict } \\
\hline Intraop event & \\
\hline Instrument defect $(\mathrm{n}=2)$ & Settled in 2 cases \\
\hline Retained foreign object & Settled \\
\hline Misplaced hardware & Settled \\
\hline Injury to normal structure $(\mathrm{n}=4)$ & $\begin{array}{c}\text { Settled in 2, dismissed in 1, } \\
\text { denied in 1 }\end{array}$ \\
\hline CSF leak during pituitary surgery & Settled \\
\hline Meningitis in context of VP shunt & Dismissed \\
placement & \\
\hline Missed diagnosis & \\
\hline Missed fracture in polytrauma & Denied \\
\hline Missed diagnosis of neurosyphilis & Dismissed \\
\hline Failure to improve $(\mathrm{n}=12)$ & Dismissed in 11, denied in 1 \\
\hline Miscellaneous & \\
\hline Nondiagnostic biopsy & Dismissed \\
\hline Positional palsy & Settled \\
\hline Decubitus ulcer & Dismissed \\
\hline Miscellaneous & Settled in 3 \\
\hline
\end{tabular}

\section{Discussion}

\section{Litigious Nature of Medical Practice}

The goal of the medical liability system is to compensate patients who have been negligently injured and to penalize and deter medical negligence. ${ }^{6,21}$ However, even though well intentioned, this system has had many unintended and undesirable consequences. Soaring malpractice insurance as well as the constant threat of litigation has negatively influenced the way many physicians practice medicine,

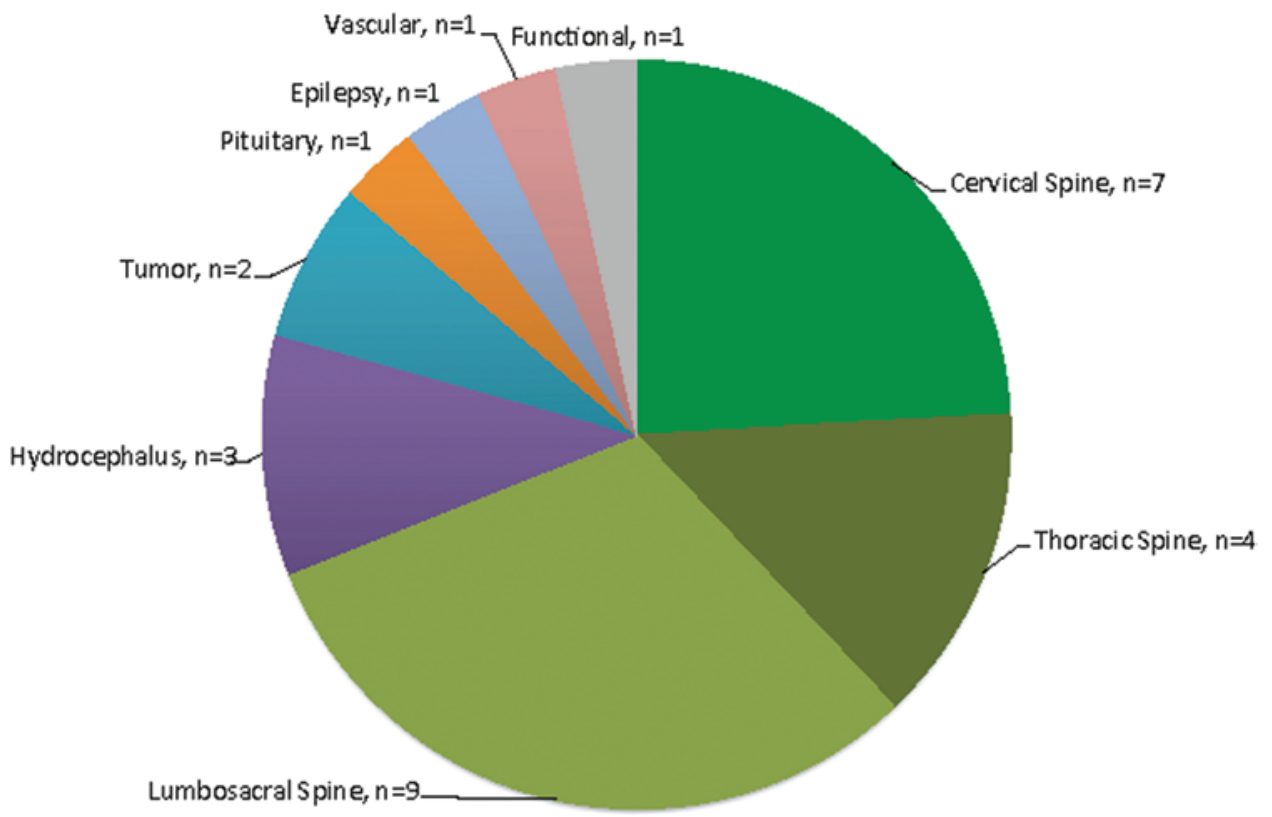

FIG. 3. Case distribution by diagnosis. 


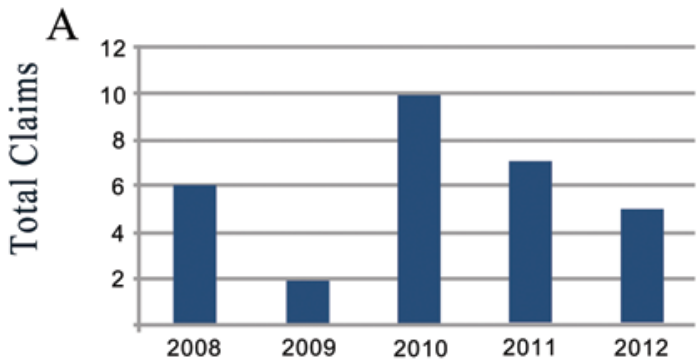

B
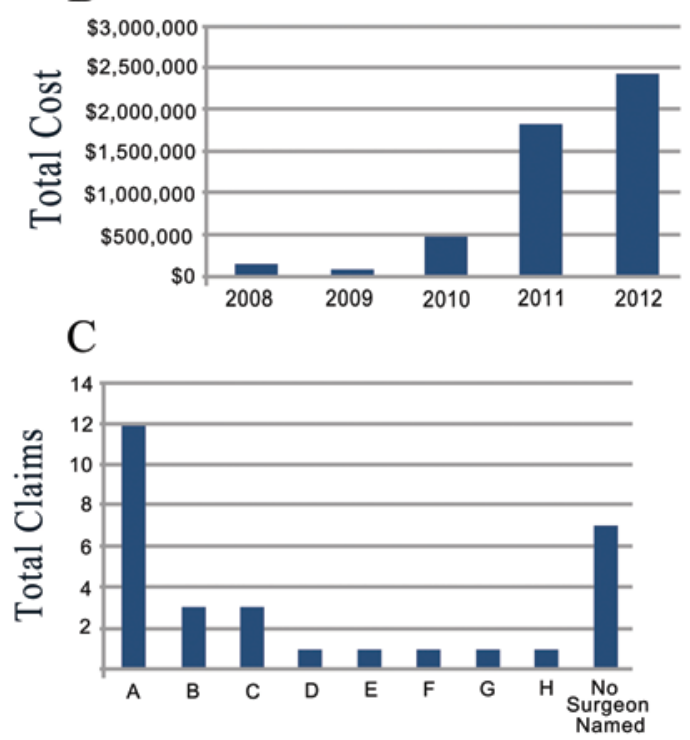

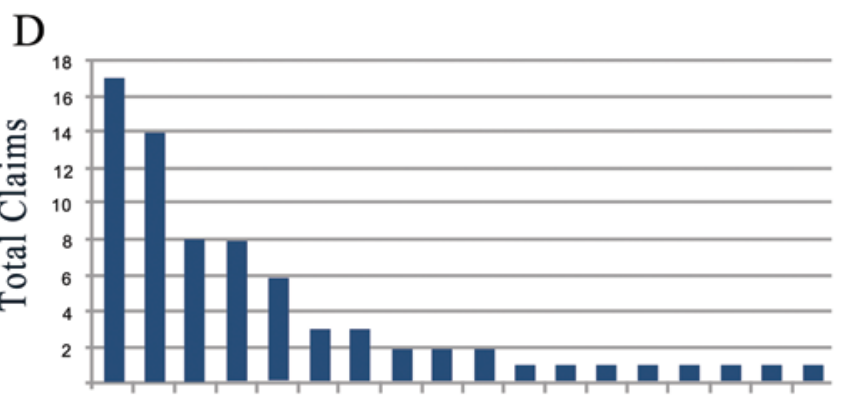

TS4 CJ1 CJ2 CO2 NI1 AD3 BR2 CJ3 DO3 TS3 AD6 CJ4 CJ6 CO1 CS4 CS9 DO9EQ1

$\mathrm{E}$

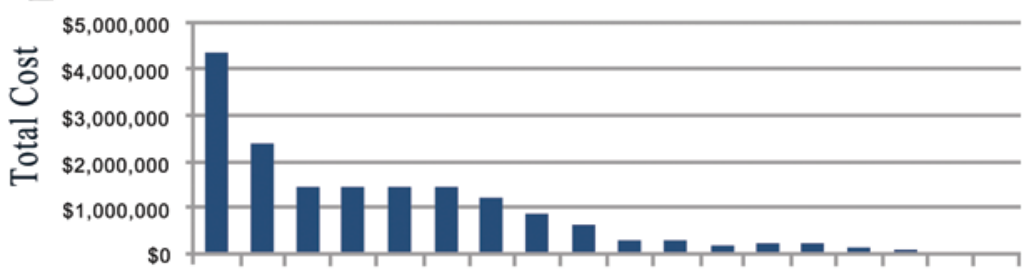

TS4 CO2 CJ2 CJ3 AD6 DO9 DO3 CJ4 CJ1 AD3 NI1 TS3 CS9 EQ1 CS4 CJ6 BR2 CO1

FIG. 4. Bar graphs showing data for the Department of Neurosurgery (RRMC and SMMC) during the study period (20082012). A: Representation of the number of claims filed per year. B: Representation of the total cost incurred per year. C: Claim count per surgeon. A letter is assigned to each surgeon enabling anonymous review of results by the group. The last bar identified as "no named surgeon" represents cases in which the medical center (RRMC or SMMC) was the only identified insured. D: Representation of total number of claims filed per contributing factors identified in the lawsuits. E: Representation of total cost incurred per contributing factors identified in the lawsuits. $A D 3=$ administrative, staff issues; $A D 6=$ administrative/other; $B R 2=$ patient factors; CJ1 = clinical judgment, patient assessment issues; CJ2 = clinical judgment, selection and management of therapy; CJ3 = clinical judgment, patient monitoring; CJ4 = clinical judgment, failure/delay in obtaining consult/referral; CJ6 = clinical judgment, conditions affecting the caregiver; $\mathrm{CO} 1=$ communication among providers; $\mathrm{CO} 2=$ communication between patient/family and providers; CS4 = lack of/failure in patient follow-up system; CS9 = clinical systems, lack of/failure in system for patient care; DO3 = insufficient/lack of documentation; DO9 = content decisions-other; EQ1 = equipment; NI1 = noninsured contributing factor issues, noninsured issues; TS3 = technical skill, retained foreign body; TS4 = technical skill, technical performance.

either limiting the type of procedures they perform or ordering excessive studies and consultations. ${ }^{1}$ The problem only seems to be getting worse. Although the number of medical malpractice jury trials has remained fairly stable between 1992 and 2001, the median damages awarded at trial has increased by nearly $70 \% .^{3}$ Medical centers often try to recover these losses through indirect costs, making care more expensive for everyone. Fortunately for physicians, less than $10 \%$ of medical malpractice cases go to trial, with many suits being either dropped or dismissed. ${ }^{6}$ Of the cases that actually go to trial, defendant health care providers prevail about $80 \%$ of the time..$^{15}$ However, even cases that are dismissed or result in a favorable ruling can result in prohibitive legal fees. To better understand the extent of this problem, we completed a detailed review of liability claims/suits within a large tertiary hospital, focusing specifically on surgical and neurosurgical services.

\section{Summary of Findings}

Consistent with national trends, we noticed that while the number of suits stayed relatively constant, the costs associated with those lawsuits increased over time. At our institution, the Department of Neurosurgery received the most lawsuits of all surgical specialties. We identified the following factors as the most frequently noted in lawsuits: clinical judgment, technical skill, and communication. The most frequent subfactors were technical performance, patient assessment issues, and selection and management of therapy (Table 3, Fig. 4). Relying on expert review, MRMC, and status of report to the Medical Board of California, it was determined that standard of care was not met in 6 cases, all of which involved spinal pathologies.

\section{Interventions to Minimize Risk Litigation}

Reporting the root cause and eventual outcome of law- 
TABLE 3. Clinical examples of the top 3 subfactors from the current series

\begin{tabular}{lll}
\hline $\begin{array}{l}\text { Top } 3 \text { Subfactors Extracted } \\
\text { From Neurosurgery Claims }\end{array}$ & $\begin{array}{l}\text { Related Contributing } \\
\text { Factor Category }\end{array}$ & \multicolumn{1}{c}{ Clinical Examples } \\
\hline Technical performance & Technical skills & 1) Misplaced lumbar screw. 2) CSF leak in spine or pituitary surgery. \\
\hline Patient assessment & Clinical judgment & $\begin{array}{l}\text { 1) Patient w/ subarachnoid hemorrhage underwent clipping, postop headache was dismissed as } \\
\text { meningeal irritation due to blood products. Abscess was later discovered (narrow diagnostic } \\
\text { focus). 2) Failure to diagnose pseudomeningocele in a spine patient w/ new postoperative } \\
\text { weakness. 3) Failure to diagnose a sinus thrombosis in a patient w/ bilateral arm weakness. }\end{array}$ \\
\hline $\begin{array}{l}\text { Selection \& management } \\
\text { of therapy }\end{array}$ & Clinical judgment & $\begin{array}{l}\text { 1) A limited surgery that is insufficient to effectively decompress spinal elements. 2) Failure to } \\
\text { adequately address pain complaints. 3) Inappropriate delay of transfer in a patient w/ acute } \\
\text { weakness due to epidural abscess. }\end{array}$ \\
\hline
\end{tabular}

suits is relatively straightforward. The challenge lies in preventing further lawsuits. The data from this study indicate that simply reducing the number of errors is only part of the solution. Much of reducing malpractice risk involves appropriate communication with patients and managing their expectations and occasional dissatisfaction. Central to this goal is the physician's ability to establish rapport, provide access, and communicate effectively.,12,23 In collaboration with the risk management department, the Department of Neurosurgery at UCLA created a departmental roadmap to reduce the number of and cost incurred from lawsuits. A series of educational symposiums covering topics such as the litigation process, risk mitigation strategies, and implications for trainees was coordinated for the faculty and the residents.

Risk litigation data were integrated in the physician report cards, which are reviewed with the department chair biannually. Importantly, if a disproportionate number of claims are associated with one specific neurosurgeon, then an individualized approach needs to be designed, including potentially training and/or reorientation. Among the 6912 cases performed at RRMC and SMMC by 15 neurosurgeons, 30 cases of litigation occurred, involving 8 neurosurgeons. A significant portion of claims was clustered around one neurosurgeon's practice (Fig. 4); this surgeon departed from the UCLA Department of Neurosurgery at UCLA during the study period. However, if claims are evenly distributed among the neurosurgeons, a more general program of education for the entire department is indicated.

Detailed review of legal actions has been coordinated every 6 months instead of once every 3-5 years. This change has enabled discussion of the claims while events are still fresh and quasi-real time identification of improvement opportunities. All contributing factors raised in all claims merit a root-cause analysis.

Monitoring of unsolicited patient complaints collected via multiple data sources (such as patient affairs and social media) has been coordinated and the results are reviewed monthly. Given they occur more frequently than a lawsuit, patients' complaints have been proposed as a surrogate identifier of risk of malpractice suits enabling early identification of physicians at risk for being sued and allowing timely and physician-specific corrective interventions. ${ }^{7,21}$

\section{Changing Culture}

Review of our risk liability data over the last 5 years identified clinical judgment as the most common contributing factor. It was noted that challenging and rare clinical situations could benefit from discussions early on with experienced colleagues to ensure that all diagnostic and treatment elements have been considered. Although collaborative work has always been fostered within the department, the leadership has more recently instituted different avenues to simplify and coordinate teamwork between colleague physicians for the benefit of patients. ${ }^{20}$

First, weekly case review with the chairman and senior colleagues was initially dedicated to reviewing upcoming cases. More recently, mortalities and selected morbidities of the previous week are also reviewed, ensuring prompt identification and correction of practice or organizational issues. Junior attending physicians have been encouraged to present cases for which the opinion of senior colleagues is sought. Second, the leadership has instituted a departmental policy that the attending on call can reach out to a colleague to obtain a second clinical opinion for complex or unusual cases. This has made some physicians feel more at ease of doing so. Third, cosurgeon assistance on challenging cases has been encouraged and supported by the department's leadership. The global message is that it is not just accepted to ask for help, the department supports and encourages this.

\section{Integration of Risk Management Data in Quality Initiatives}

In April 2013, the Department of Neurosurgery at UCLA launched a multidisciplinary and multidepartmental care redesign strategy initiative, called NERVS (Neurosurgery Enhanced Recovery after surgery, Value, and Safety), to improve neurosurgery valued care. As we assessed the current state of our clinical processes, clinical outcomes, and cost of care delivery, we recognized the importance of integrating additional unconventional data as we strategized to improve the value of delivered care. Comprehensive assessment of our baseline safety events, patient satisfaction data, and risk liability data showed to be invaluable. Recognizing that technical skill was the second most common contributing factor, the NERVS care redesign initiative integrated the actual surgery as a standalone point of the care pathway to process map. Communication was the third most common contributing factor in neurosurgery claims and was ranked the most important care item within the NERVS care redesign initiative to improve overall patient care. Capturing risk liability-related data enabled us to integrate specific surgical processes in 
the care redesign strategy and confirm alignment of priorities between the care redesign strategy and risk management department. An ensemble of process improvement initiatives is being implemented to improve communication among care providers and enhance transition of care.

\section{Conclusions}

Lawsuits and legal action can be stressful for everyone involved, from the attending physician to the department to the medical system as a whole. While it is a worthy goal to minimize the number of lawsuits, the ultimate goal should always be to provide the optimal value of care, delivering the best quality of care at the lowest cost. ${ }^{16,17}$ In comparing our experience with others found in the literature we found several lessons that are common to private and academic centers alike across multiple specialties. ${ }^{10}$ First, simply making a safer operative environment is not always sufficient as some patients will always be disappointed when outcomes do not meet their expectations. The key to minimizing this risk is clear perioperative communication and documentation with the patient and his/her family, with realistic moderation of expectations. ${ }^{14}$ Next, real surgical errors and equipment failures do occur. While each error in isolation stems from one person or piece of equipment, they occur in a setting of multiple verifications and reverification. Therefore, solutions to these problems require a systems-level approach and a blamefree environment to encourage open and honest discussion and root-cause analysis. Last, integrating risk management department-specific and physician-specific data in care redesign initiatives is strategic, enabling alignment of efforts to minimize litigation and its financial impact, and most importantly favorably impact care delivery.

\section{References}

1. Adamo MA, Popp JR, Popp AJ: Neurosurgery and medical malpractice litigation. Part II: Malpractice claims in neurosurgery. Contemp Neurosurg 31:1-5, 2009

2. American Association of Neurological Surgeons, Congress of Neurological Surgeons, Council of State Neurosurgical Societies: Neurosurgery in a State of Crisis: Report on the State of Professional Liability Insurance Rates and the Impact on Neurosurgeons and Their Patients. Park Ridge, IL: American Association of Neurological Surgeons, 2002

3. Cohen TH, Hughes KA: Medical Malpractice Insurance Claims in Seven States, 2000-2004. Bureau of Justice Statistics. (http://www.bjs.gov/content/pub/pdf/mmicss04.pdf) [Accessed November 29, 2014]

4. Crico Coding Manual. Boston: Risk Management Foundation of the Harvard Medical Institutions, 2011

5. Fager CA: Malpractice issues in neurological surgery. Surg Neurol 65:416-421, 2006

6. Floyd TK: Medical malpractice: trends in litigation. Gastroenterology 134:1822-1825.e1, 2008

7. Hickson GB, Federspiel CF, Pichert JW, Miller CS, GauldJaeger J, Bost P: Patient complaints and malpractice risk. JAMA 287:2951-2957, 2002

8. Howard PK: Medical Tort Reform Could Save Billions. Washington Post. July 31, 2009. (http://www. washingtonpost.com/wp-dyn/content/article/2009/07/30/ AR2009073002816.html) [Accessed November 29, 2014]

9. Jena AB, Seabury S, Lakdawalla D, Chandra A: Malprac- tice risk according to physician specialty. N Engl J Med 365:629-636, 2011

10. Knaak JP, Parzeller M: Court decisions on medical malpractice. Int J Legal Med 128:1049-1057, 2014

11. Mello MM, Studdert DM, DesRoches CM, Peugh J, Zapert $\mathrm{K}$, Brennan TA, et al: Effects of a malpractice crisis on specialist supply and patient access to care. Ann Surg 242:621628, 2005

12. Murff HJ, France DJ, Blackford J, Grogan EL, Yu C, Speroff T, et al: Relationship between patient complaints and surgical complications. Qual Saf Health Care 15:13-16, 2006

13. Nahed BV, Babu MA, Smith TR, Heary RF: Malpractice liability and defensive medicine: a national survey of neurosurgeons. PLoS ONE 7:e39237, 2012

14. Nebel EJ: Malpractice: love thy patient. Clin Orthop Relat Res (407):19-24, 2003

15. Oetgen WJ, Parikh PD, Cacchione JG, Casale PN, Dove JT, Harold JG, et al: Characteristics of medical professional liability claims in patients with cardiovascular diseases. Am J Cardiol 105:745-752, 2010

16. Porter ME: Value-based health care delivery. Ann Surg 248:503-509, 2008

17. Porter ME: What is value in health care? $\mathbf{N}$ Engl J Med 363:2477-2481, 2010

18. Rovit RL, Simon AS, Drew J, Murali R, Robb J: Neurosurgical experience with malpractice litigation: an analysis of closed claims against neurosurgeons in New York State, 1999 through 2003. J Neurosurg 106:1108-1114, 2007

19. Rubin RJ, Mendelson DN: How much does defensive medicine cost? J Am Health Policy 4:7-15, 1994

20. Sammer CE, Lykens K, Singh KP, Mains DA, Lackan NA: What is patient safety culture? A review of the literature. J Nurs Scholarsh 42:156-165, 2010

21. Saxton J: Liability for medical malpractice: issues and evidence. A Joint Economic Committee study. N J Med 100:13-19, 2003

22. Spetzler RF, Kick SA: The status of neurosurgery in the United States: 2010 and beyond. World Neurosurg 74:3240,2010

23. Stimson CJ, Pichert JW, Moore IN, Dmochowski RR, Cornett MB, An AQ, et al: Medical malpractice claims risk in urology: an empirical analysis of patient complaint data. J Urol 183:1971-1976, 2010

24. Studdert DM, Mello MM, Sage WM, DesRoches CM, Peugh J, Zapert K, et al: Defensive medicine among high-risk specialist physicians in a volatile malpractice environment. JAMA 293:2609-2617, 2005

25. Summerton N: Positive and negative factors in defensive medicine: a questionnaire study of general practitioners. BMJ 310:27-29, 1995

\section{Author Contributions}

Conception and design: Martin, McLaughlin, Klohn. Acquisition of data: McLaughlin, Garrett, Emami, Foss. Analysis and interpretation of data: all authors. Drafting the article: McLaughlin, Garrett. Critically revising the article: Martin, McLaughlin, Garrett, Foss, Klohn. Reviewed submitted version of manuscript: Martin, McLaughlin, Garrett. Administrative/technical/material support: Foss, Klohn. Study supervision: Martin, McLaughlin.

\section{Correspondence}

Neil A. Martin, Department of Neurosurgery, David Geffen School of Medicine, 757 Westwood Plaza, Ste. 6236, Los Angeles, CA 90095-7436. email: neilmartin@mednet.ucla.edu. 